Article

\title{
Vaccine Hesitancy: COVID-19 and Influenza Vaccine Willingness among Parents in Wuxi, China-A Cross-Sectional Study
}

\author{
Qiang Wang ${ }^{1,2,+}$, Shixin Xiu ${ }^{3, \dagger}$, Shuangyu Zhao ${ }^{1,2}$, Jianli Wang ${ }^{1,2}$, Ying Han ${ }^{1,2}$, Shuheng Dong ${ }^{1,2}$, \\ Jinxin Huang ${ }^{1,2}$, Tingting Cui ${ }^{1,2}$, Liuqing Yang ${ }^{1,2}$, Naiyang Shi ${ }^{1,2}$, Minqi Liu ${ }^{1,2}$, Yue Han ${ }^{1,2}$, Xuwen Wang ${ }^{3}$, \\ Yuan Shen ${ }^{3}$, Enpin Chen ${ }^{3}$, Bing Lu ${ }^{3}$, Hui Jin ${ }^{1,2, *}$ (i) and Leesa Lin ${ }^{4}$
}

check for updates

Citation: Wang, Q.; Xiu, S.; Zhao, S.; Wang, J.; Han, Y.; Dong, S.; Huang, J.; Cui, T.; Yang, L.; Shi, N.; et al. Vaccine Hesitancy: COVID-19 and Influenza Vaccine Willingness among Parents in Wuxi, China-A Cross-Sectional Study. Vaccines 2021, 9, 342. https:// doi.org/10.3390/vaccines 9040342

Academic Editors: Ju-Young Shin and Shawn Babiuk

Received: 23 February 2021

Accepted: 22 March 2021

Published: 1 April 2021

Publisher's Note: MDPI stays neutral with regard to jurisdictional claims in published maps and institutional affiliations.

Copyright: (c) 2021 by the authors. Licensee MDPI, Basel, Switzerland. This article is an open access article distributed under the terms and conditions of the Creative Commons Attribution (CC BY) license (https:/ / creativecommons.org/licenses/by/ $4.0 /)$.
1 Department of Epidemiology and Health Statistics, School of Public Health, Southeast University, Nanjing 210009, China; 230198325@seu.edu.cn (Q.W.); 213181074@seu.edu.cn (S.Z.); 213171070@seu.edu.cn (J.W.); 220193551@seu.edu.cn (Y.H.); 213172733@seu.edu.cn (S.D.); 220183468@seu.edu.cn (J.H.); 230189704@seu.edu.cn (T.C.); 230208397@seu.edu.cn (L.Y.); 220183431@seu.edu.cn (N.S.); 220193555@seu.edu.cn (M.L.); 220193593@seu.edu.cn (Y.H.)

2 Key Laboratory of Environmental Medicine Engineering, School of Public Health, Southeast University, Ministry of Education, Nanjing 210009, China

3 Wuxi Center for Disease Control and Prevention, Wuxi 214023, China; wxcdcsx@163.com (S.X.); wxmgwang@163.com (X.W.); wxcdcshy@163.com (Y.S.); chenepxia@163.com (E.C.); Lub19661023@163.com (B.L.)

4 Department of Infectious Disease Epidemiology, London School of Hygiene and Tropical Medicine, Keppel Street, London WC1E 7TH, UK; Leesa.Lin@1shtm.ac.uk

* Correspondence: jinhuihld@seu.edu.cn; Tel.: +86-025-8327-2572; Fax: +825-83272561

+ Contributed equally.

Abstract: Objectives: We aimed to (1) assess parental hesitancy about category A (Expanded Program on Immunization (EPI)) and B (non-EPI) vaccines, (2) assess parental willingness for COVID-19 and influenza vaccinations, and (3) explore the association of vaccination hesitancy of parents and healthcare workers (HCWs). Methods: The study was performed in Wuxi, eastern China between 21 September 2020 and 17 October 2020. Parents of children aged $<18$ years and HCWs were recruited from the selected immunization clinics. Vaccine hesitancy was assessed using the Strategic Advisory Group of Experts (SAGE) vaccine hesitancy survey (VHS) by summing the total score for 10 items (maximum 50 points). Results: A total of 3009 parents and 86 HCWs were included in the analysis. The category A VHS scores were significantly higher than the category B VHS scores $(p=0.000)$. Overall, $59.3 \%$ and $52.4 \%$ of parents reported willingness to avail COVID-19 and influenza vaccination for their children, respectively; $51.2 \%$ of the HCWs wanted to be vaccinated against COVID-19. Parental category B VHS scores were associated with HCW category B VHS scores $(r=0.928, p=0.008)$. Conclusions: In China, parents are more hesitant about category B vaccines than category A vaccines. More than $40 \%$ of parents showed hesitancy and a refusal to use COVID-19 and influenza vaccines.

Keywords: parents; vaccine hesitancy; COVID-19 vaccine; influenza vaccine; willingness

\section{Introduction}

Vaccine hesitancy was named one of the top 10 issues threatening global health in 2019 [1]. Vaccine hesitancy is defined by World Health Organization Strategic Advisory Group of Experts (SAGE) as the delay in acceptance or refusal of vaccination despite the availability of vaccination services [2].

Children are important targets of routine vaccinations, and parental vaccine hesitancy results in a decrease in vaccine uptake among children. This has in turn led to the surge of many vaccine-preventable diseases, such as measles [3]. In 2018, the largest measles 
outbreak occurred in New York City, USA in nearly 30 years [4]. In European Union countries, 148,279 measles cases were reported between 2010 and 2019 [5].

Influenza-vaccine uptake among children attracts the attention of health authorities and researchers. More parents $(25.8 \%)$ showed hesitancy about the influenza vaccine compared with other routine childhood vaccines $(6.1 \%)[6]$. The psychosocial factors (including necessity and safety of a vaccination for a child, etc.) contributed to parental hesitancy on influenza vaccines [7-9]. However, the influenza willingness rate has been reported to increase during the COVID-19 pandemic [10,11].

The current coronavirus disease 2019 (COVID-19) pandemic has caused more than 2.14 million deaths [12], and vaccination is key to controlling it. In a global survey, $54.85-88.62 \%$ of the respondents showed willingness to receive the COVID-19 vaccine [13]. Among parents, an international survey of six countries showed that $65 \%$ of parents were willing to vaccinate their child [14]. An estimated $60-72 \%$ coverage is needed to reach the herdimmunity threshold to control the spread of COVID-19 [15]. Vaccination for children may be an important part of achieving herd immunity.

In China, vaccine hesitancy needs attention: $24.9 \%$ of parents showed hesitancy to get all the recommended vaccinations for their child(ren) [16]. Meanwhile, the influenza vaccine is not regarded as important. A meta-analysis of 126 studies showed that influenzavaccine coverage among children was lower than $30 \%$ in mainland China [17]. Approximately $20 \%$ of participants surveyed in China showed hesitancy toward the COVID-19 vaccination $[13,18]$.

However, some issues remain unclear. Vaccination programs in China are divided into the Expanded Program on Immunization (EPI) and the non-Expanded Program on Immunization (non-EPI) [19]. Routine vaccines introduced in the EPI are referred to as category $\mathrm{A}$ and are free and mandatory. Meanwhile, non-EPI vaccines are referred to as category $\mathrm{B}$ and are optional and self-pay. Parental vaccine hesitancy might be distinctly different for categories A and B vaccines. Further, parents' willingness regarding the COVID-19 and influenza vaccinations (category $B$ vaccine) and associated factors were not clear in China. Obtaining data on Chinese parents' intentions for the COVID-19 and influenza vaccines could help inform the development of child immunization policies to effectively address COVID-19 and influenza vaccine hesitancy and improve uptake in China.

The previous studies suggested that recommendations from healthcare workers (HCWs) were influencing factors of vaccine uptake among the general population $[17,20,21]$. HCWs working in immunization clinics have direct contact with parents, and $\mathrm{HCWs}^{\prime}$ attitudes and beliefs on vaccination play a role in parents' immunization decisions [20]. However, few studies have examined the relationship between HCWs in immunization clinics and vaccine hesitancy among parents.

Thus, this study aimed to (1) assess and compare the level of hesitancy between category A and B vaccines, and the sociodemographic factors associated with vaccine hesitancy, in Chinese parents; (2) assess the parents' willingness to acquire COVID-19 and influenza vaccines for their children, and the sociodemographic factors associated with vaccination willingness; (3) examine the association between routine vaccine hesitancy and COVID-19 vaccine willingness; and (4) explore the association between vaccine hesitancy among parents and HCWs in immunization clinics.

\section{Methods}

\subsection{Study Design and Participants}

This cross-sectional study was performed in Wuxi City, eastern China (total population: 6.59 million in 2018) between 21 September 2020 and 17 October 2020 (Figure S1). We recruited participants from local community health service center immunization clinics. The immunization clinics provide vaccination services for children and adults, and the main service populations are children aged $<6$ years. The participants were fathers or mothers of children aged $<18$ years. Only those who have lived in Wuxi City for more than 
3 years were eligible. If both the father and mother came to the vaccination clinic, the parent who self-identified as the primary caregiver for the child completed the questionnaire.

The vaccination clinic was selected using a stratified sampling method. First, areas and counties in Wuxi City (Figure S2) were divided into three levels based on economic characteristics in 2019 (gross domestic product) [22]. One area was selected from each level, and two clinics in each area were selected using a random number. The HCWs in all six sampled immunization clinics were all included in the study.

The sample size was calculated using the following formula:

$$
N_{\text {min }}=\operatorname{deff} \times \frac{Z^{2}(1-\alpha) / 2 \times p \times(1-p)}{d^{2}}
$$

The type I error $(\alpha)$ was 0.05 , the precision $(d)$ was 0.04 , and the design effect (deff) was 2 [16,23]. A 50\% vaccine hesitancy rate (to get the largest sample size) was used because this number was not given in the previous study. The minimum target sample size was calculated to be 2081 .

\subsection{Measures}

The parental questionnaire consisted of three parts: sociodemographic information, the vaccine-hesitancy scale (VHS), and COVID-19 and influenza vaccine willingness. The sociodemographic portion included information for children (date of birth, gender, firstborn status) and parents (relationship with child, date of birth, educational level, annual household income, and healthcare occupation). We divided educational level into four groups: junior high school or below, high school graduate or equivalent, college or equivalent, and master's diploma or above. Annual household income was divided into four groups with reference to the per capita disposable income (RMB 54,847; USD $1=$ RMB 6.8148) in Wuxi in 2019 [24]: <RMB 50,000; RMB 50,000-<100,000; RMB 100,000-<150,000; and $\geq$ RMB 150,000.

Vaccine hesitancy about category A and B vaccines was assessed on a 5-point Likert scale using the SAGE 10-item VHS (Table 1) [25]. The 10-item VHS has acceptable reliability and validity, and has been used in numerous countries previously [6,26-28]. Each item was answered as strongly disagree, disagree, neither agree nor disagree, agree, or strongly agree. In the questionnaire, we replaced "category A" with "free", and "category B" with "selfpay" because of the common names used by parents, in order to improve comprehension of the questionnaire.

Table 1. The 10-item Likert scale.

\begin{tabular}{|c|c|}
\hline No. & Content \\
\hline L1 & Childhood vaccines are important for my child's health \\
\hline L2 & Childhood vaccines are effective \\
\hline L3 & Having my child vaccinated is important for the health of others in my community \\
\hline L4 & $\begin{array}{l}\text { All childhood vaccines offered by the government program in my community } \\
\text { are beneficial }\end{array}$ \\
\hline L5 & New vaccines carry more risks than older vaccines \\
\hline L6 & $\begin{array}{c}\text { The information I receive about vaccines from the vaccine program is reliable } \\
\text { and trustworthy }\end{array}$ \\
\hline L7 & Getting vaccines is a good way to protect my child/children from disease \\
\hline L8 & $\begin{array}{l}\text { Generally I do what my doctor or healthcare provider recommends about vaccines } \\
\text { for my child/children }\end{array}$ \\
\hline L9 & I am concerned about serious adverse effects of vaccines \\
\hline L10 & $\begin{array}{l}\text { My child/children does/do not need vaccines for diseases that are not } \\
\text { common anymore }\end{array}$ \\
\hline
\end{tabular}

COVID-19 and influenza vaccine willingness were measured using two questions: "If COVID-19 vaccine is available, will you vaccinate for your child?" and "Will you vaccinate 
your child against influenza this year?" The answers available for the two questions were "yes", "not sure", and "no." Two follow-up questions on COVID-19 vaccine willingness were added: "If you choose 'yes,' why?" and "If you choose 'not sure' or 'no,' why?". The participants who reported willingness to receive a COVID-19 vaccination for their child answered another two questions: "Do you want your child to be the first population to receive the COVID-19 vaccine" (yes/no/not sure) and "Will you choose domestic or foreign COVID-19 vaccine for your child?" (domestic/foreign/not sure).

Responses to the VHS questionnaire were assigned scores as follows: strongly disagree, 1 point; disagree, 2 points; neither agree nor disagree, 3 points; agree, 4 points; and strongly agree, 5 points. Responses to items L5, L9, and L10 were flipped because these three questions were worded negatively. The total score for all 10 items was summed, and total maximum score was 50 points. Lower scores represented higher vaccine hesitancy. We used the cutoff of total scores $\leq 30$ to define "high hesitant" because this value indicated hesitancy level was the midpoint of scale scores [6]. We also set the cutoff value to $\leq 40$ to perform the sensitive analysis.

The questionnaire for the HCWs also consisted of three parts: sociodemographic, VHS, and COVID-19 vaccine willingness. The sociodemographic portion included questions regarding gender, educational level, specialty, title, working years, and annual household income. Meanwhile, VHS and COVID-19 vaccine willingness were similar to the parents' questionnaires.

\section{Quality Control and Statistical Analysis}

Data from the questionnaires were entered into EpiData 3.1 software, and all data were entered twice. Questionnaires with at least three missing answers were excluded. The missing data were filled using multiple imputation methods [29]. The methods and results validation of questionnaire are shown in Supplementary 2: Method. The results suggested that the reliability and validity of the 10-item VHS were acceptable.

Data were reported using descriptive statistics. Normally and non-normally distributed continuous variables were analyzed using the $\mathrm{t}$-test and the Mann-Whitney $\mathrm{U}$ test, respectively. Meanwhile, categorical variables were compared using the Chi-square or Fisher's exact test. The Spearman correlation was used to describe the relationship between VHS scores and vaccination willingness. Meanwhile, we reported the relationship between VHS scores and vaccination willingness between HCWs and parents divided by immunization clinics (using mean values).

The ( $\beta$ ) coefficient and its $95 \%$ confidence interval (CI) of each variable were estimated using a generalized linear model with a maximum likelihood method to identify the influencing factors of vaccine hesitancy $[30,31]$. The odds ratio (OR) and $95 \% \mathrm{CI}$ were used to explore the influencing factors of COVID-19 and influenza willingness, using logistic regression analysis. In this analysis, we combined the responses "no" and "not sure" into "no" because they both indicated a lack of confidence. Significant variables in the univariate analysis were included in the multivariate analysis. The results of significant variables were reported in the multivariate analysis. The false discovery rate (FDR) method was used to adjust the $p$ value to control the error rate among significant results [32]. All statistical analyses were performed using $\mathrm{R}$ software. A two-sided $p$ value of $<0.05$ was considered statistically significant.

\section{Results}

\subsection{Sociodemographic Characteristics of the Participants}

Of the 3079 questionnaires collected, 3009 questionnaires were included in the analysis (Figure 1). The average participant age was 31.36 years old, and $74.6 \%$ were mothers (Table 2). Overall, $69.7 \%$ had a college degree or above, and $93.8 \%$ did not have a healthcare occupation. 


\section{9 questionnaires collected}

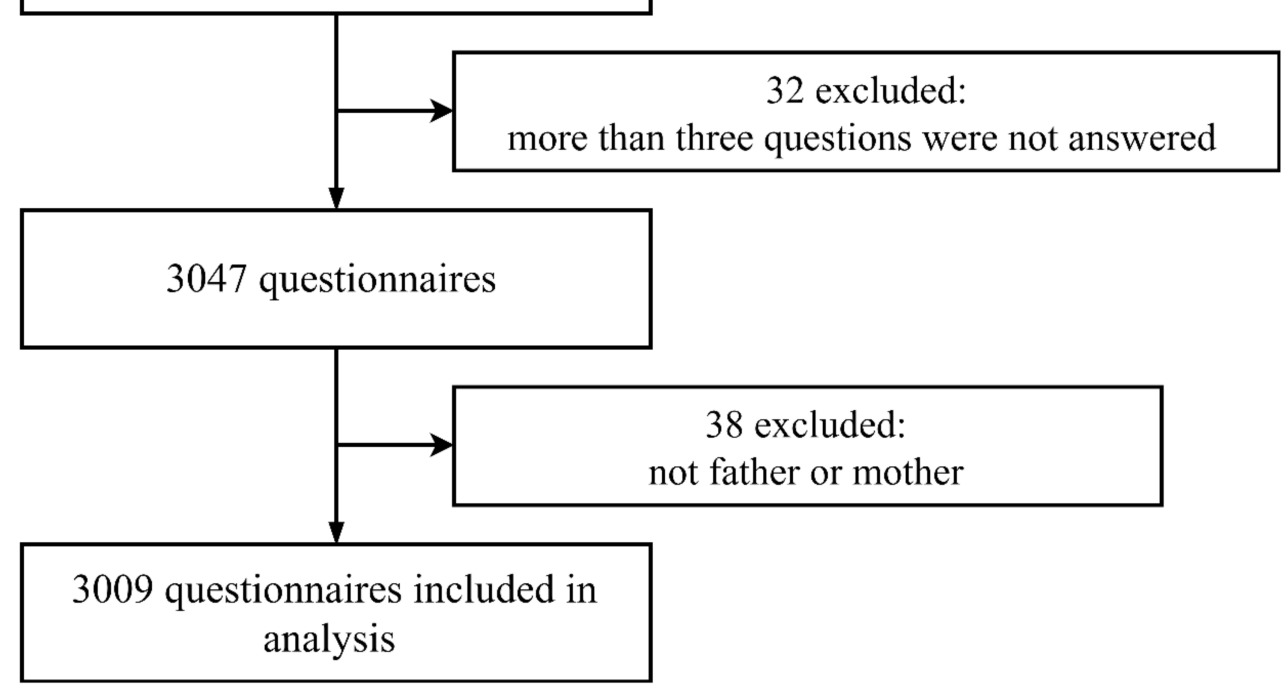

Figure 1. Flow chart for parent questionnaires.

Table 2. Participants' sociodemographic information.

\begin{tabular}{cc}
\hline Sociodemographics & Data, N (\%) \\
\hline Children & - \\
Age, year (Mean \pm SD) & $2.24 \pm 2.47$ \\
Age group & - \\
$<1$ & $1067(35.5)$ \\
$1-<2$ & $467(15.5)$ \\
$2-<3$ & $321(10.7)$ \\
$3-<4$ & $298(9.9)$ \\
$4-<5$ & $313(10.4)$ \\
$5-<6$ & $142(4.7)$ \\
$\geq 6$ & $401(13.3)$ \\
Gender & - \\
Male & $1528(50.8)$ \\
Female & $1481(49.2)$ \\
Firstborn & - \\
Yes & $1982(65.9)$ \\
No & $1027(34.1)$ \\
Parents & - \\
Mother & - \\
Father & $2245(74.6)$ \\
Age, year(Mean \pm SD) & $764(25.4)$ \\
Agroup & $31.36 \pm 4.46$ \\
$<26$ & - \\
\end{tabular}


Table 2. Cont.

\begin{tabular}{|c|c|}
\hline Sociodemographics & Data, N (\%) \\
\hline $26-<31$ & $1091(36.3)$ \\
\hline $31-<36$ & $1162(38.6)$ \\
\hline $36-<41$ & $417(13.9)$ \\
\hline$\geq 41$ & $90(3.0)$ \\
\hline Educational level & - \\
\hline Junior high school or below & 349 (11.6) \\
\hline High school graduate or equivalent & $563(18.7)$ \\
\hline College or equivalent & $1878(62.4)$ \\
\hline Master's Diploma or above & $219(7.3)$ \\
\hline Annual household income (RMB 10,000) & - \\
\hline$<5$ & $213(7.1)$ \\
\hline $5-<10$ & $876(29.1)$ \\
\hline $10-<15$ & $780(25.9)$ \\
\hline$\geq 15$ & $1140(37.9)$ \\
\hline Healthcare occupation & - \\
\hline Yes $^{1}$ & $186(6.2)$ \\
\hline No & $2823(93.8)$ \\
\hline Healthcare workers & - \\
\hline Age, year $($ Mean $\pm S D)$ & $36.02 \pm 9.44$ \\
\hline Gender & - \\
\hline Male & $20(23.3)$ \\
\hline Female & $66(76.7)$ \\
\hline Educational level & - \\
\hline High school graduate or equivalent & $5(5.8)$ \\
\hline College or equivalent & $81(94.2)$ \\
\hline Specialty & - \\
\hline Public health & $27(30.2)$ \\
\hline Clinical medicine & $10(11.6)$ \\
\hline Nursing & $45(52.3)$ \\
\hline Others & $5(5.8)$ \\
\hline Title & - \\
\hline Junior & $47(53.5)$ \\
\hline Intermediate & $22(25.6)$ \\
\hline Senior & $15(17.4)$ \\
\hline Others & $3(3.5)$ \\
\hline Working years & - \\
\hline$<1$ & $1(1.2)$ \\
\hline $1-<5$ & $19(22.1)$ \\
\hline $5-<10$ & $21(24.4)$ \\
\hline $10-<15$ & $13(15.1)$ \\
\hline$\geq 15$ & $32(37.2)$ \\
\hline Annual household income (RMB 10,000$)$ & - \\
\hline$<5$ & $6(7.0)$ \\
\hline $5-<10$ & $17(19.8)$ \\
\hline $10-<15$ & $24(27.9)$ \\
\hline$\geq 15$ & $39(45.3)$ \\
\hline
\end{tabular}

USD 1 = RMB 6.8148. The currency-exchange data was retrieved from http://www.pbc.gov.cn/diaochatongiisi/ resource/cms/2020/10/2020101616110773362.htm (accessed on 29 December 2020, Nanjing, Jiangsu, China).

Meanwhile, $86 \mathrm{HCWs}$ with an average age of 36.02 years completed the questionnaire. A total of $76.7 \%$ of the HCWs were female, and more than $50 \%$ had $>10$ years of working experience.

\subsection{Parental Vaccine Hesitancy}

The mean \pm SD category A VHS scores were significantly higher than the category B VHS scores ( $40.96 \pm 3.87$ vs. $38.58 \pm 5.05, p=0.000)$. For items L1-L4 and L6-L8, parents showed more agreement on category A vaccines than category B vaccines (Figure 2). Overall, $0.5 \%$ and $6.8 \%$ of parents were "high hesitant" about category A and B vaccines, 
respectively, when the cutoff was $\leq 30$. When the cutoff was $\leq 40,46.5 \%$ and $64.5 \%$ of parents were "high hesitant" about category A and B vaccines, respectively. The fathers' scores were also significantly higher than the mothers' scores for category A and B VHS (Table S1).

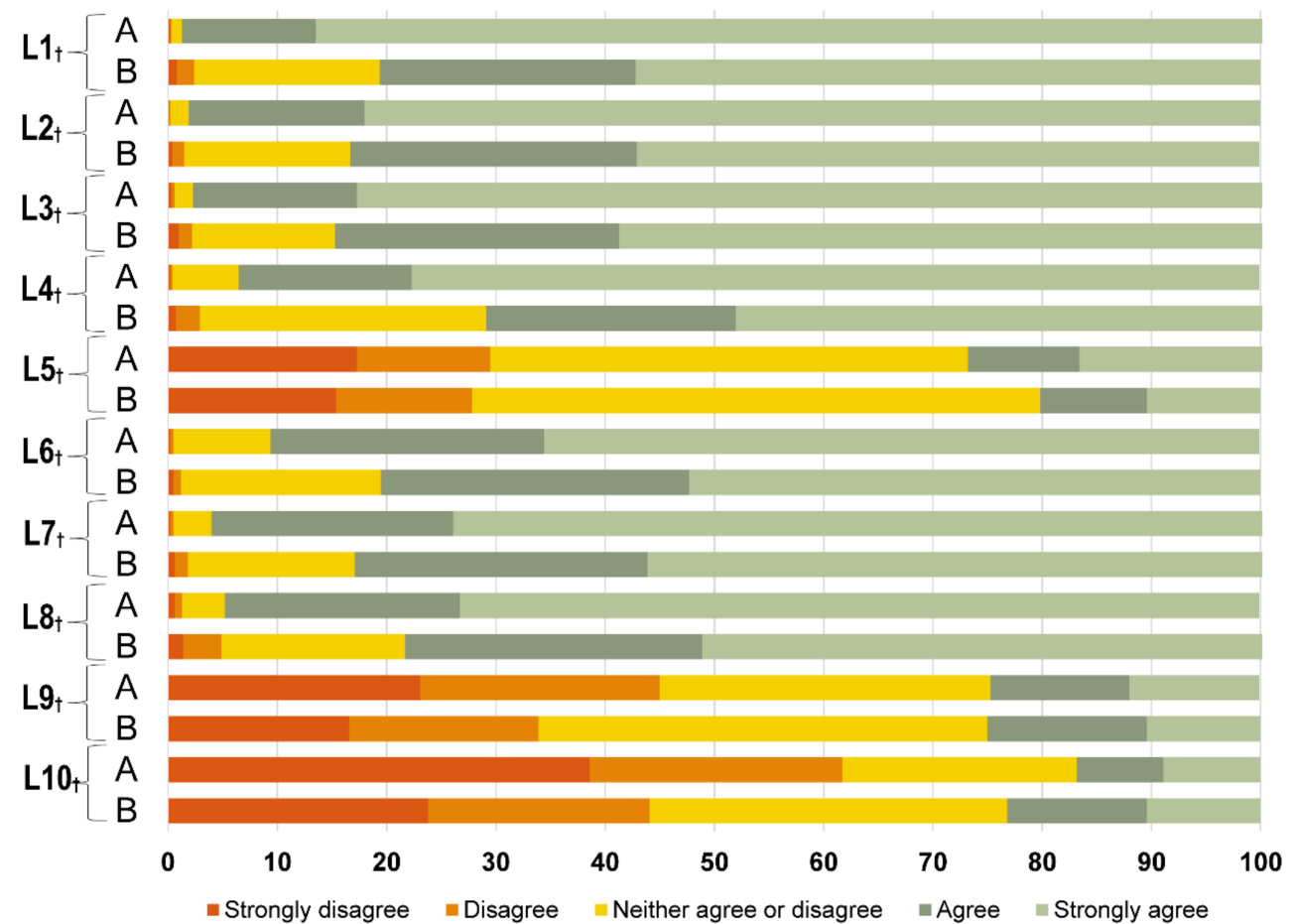

Figure 2. Distribution of parental responses to the 10 items on the vaccine-hesitancy scale. ${ }^{\dagger} p<0.05$. $\mathrm{A}=$ category $\mathrm{A}$ vaccine; $\mathrm{B}=$ category $\mathrm{B}$ vaccine.

The multivariate analysis (Table 3 ) showed that compared with mothers, fathers showed less hesitancy on category A ( $\beta: 0.011,95 \%$ CI: $0.003,0.019, p=0.012)$ and B vaccines ( $\beta: 0.013,95 \%$ CI: $0.002,0.024, p=0.023$ ). Compared with parents having annual household income $<$ RMB 50,000, parents having annual household income RMB 50,000-<10,000 showed less hesitancy on category A vaccines ( $\beta$ : 0.008, 95\% CI: 0.000, 0.016, $p=0.042$ ). 
Table 3. Univariate and multivariate factors of parental category A and B vaccine hesitancy.

\begin{tabular}{|c|c|c|c|c|c|c|c|c|}
\hline \multirow{2}{*}{ Characteristic } & \multicolumn{4}{|c|}{ Category A VHS } & \multicolumn{4}{|c|}{ Category B VHS } \\
\hline & $\begin{array}{l}\text { Univariate, } \\
\beta(95 \% \mathrm{CI})\end{array}$ & $p$ Value & $\begin{array}{c}\text { Multivariate, } \\
\beta(95 \% \text { CI })\end{array}$ & $p$ Value * & Univariate, $\beta(95 \% \mathrm{CI})$ & $p$ Value & $\begin{array}{c}\text { Multivariate, } \\
\beta(95 \% \mathrm{CI})\end{array}$ & $p$ Value * \\
\hline \multicolumn{9}{|l|}{ Children } \\
\hline$\underset{<1}{\text { Age group }}$ & & - & Reference & - & & - & - & - \\
\hline $\begin{array}{c}<1 \\
1 \text { to }<2\end{array}$ & $\begin{array}{c}\text { Reference } \\
-0.002(-0.013,0.008)\end{array}$ & $0 . \overline{6} 47$ & $\begin{array}{c}\text { Reference } \\
\quad\end{array}$ & - & $\begin{array}{c}\text { Reference } \\
0.005(-0.010,0.019)\end{array}$ & $\overline{0 .}+\overline{5} 2$ & - & - \\
\hline 2 to $<3$ & $0.000(-0.012,0.012)$ & 0.992 & \multirow{2}{*}{$\begin{array}{c}- \\
-0.018(-0.029 \\
-0.006)\end{array}$} & - & $-0.012(-0.029,0.005)$ & 0.153 & - & - \\
\hline 3 to $<4$ & $-0.021(-0.034,-0.009)$ & 0.001 & & 0.012 & $-0.010(-0.028,0.007)$ & 0.250 & - & - \\
\hline 4 to $<5$ & $-0.013(-0.025,-0.001)$ & 0.038 & $-0.000)$ & - & $-0.003(-0.020,0.014)$ & 0.718 & - & - \\
\hline 5 to $<6$ & $-0.004(-0.021,0.013)$ & 0.638 & - & - & $-0.002(-0.026,0.021)$ & 0.845 & - & - \\
\hline \multicolumn{9}{|l|}{ Gender } \\
\hline Male & Reference & - & - & - & Reference & - & - & - \\
\hline Female & $-0.004(-0.011,0.003)$ & 0.286 & - & - & $-0.003(-0.013,0.007)$ & 0.530 & - & - \\
\hline \multicolumn{9}{|l|}{ Firstborn } \\
\hline No & Reference & - & \multirow{2}{*}{$\begin{array}{c}\text { Reference } \\
-0.010(-0.017 \\
-0.003)\end{array}$} & - & Reference & - & - & - \\
\hline Yes & $-0.009(-0.016,-0.002)$ & 0.018 & & 0.012 & $0.004(-0.006,0.014)$ & 0.435 & - & - \\
\hline \multirow{2}{*}{\multicolumn{9}{|c|}{$\begin{array}{c}\text { Parents } \\
\text { Relationship with child }\end{array}$}} \\
\hline & & & & & & & & \\
\hline Mother & Reference & - & Reference & - & Reference & - & Reference & - \\
\hline \multirow{2}{*}{\multicolumn{9}{|c|}{$\begin{array}{l}\text { Fatner } \\
\text { Age group }\end{array}$}} \\
\hline & & & & & & & & \\
\hline 31 to $<36$ & $0.007(-0.007,0.020)$ & 0.316 & - & - & $0.010(-0.009,0.028)$ & 0.314 & - & - \\
\hline 36 to $<41$ & $0.006(-0.009,0.022)$ & 0.418 & - & - & $0.008(-0.013,0.029)$ & 0.463 & - & - \\
\hline$\geq 41$ & $0.018(-0.006,0.041)$ & 0.136 & - & - & $0.023(-0.010,0.056)$ & 0.165 & - & - \\
\hline \multicolumn{2}{|l|}{ Educational level } & & - & - & Reference & - & - & - \\
\hline High school graduate & $-0.003(-0.016,0.010)$ & 0.697 & - & - & $0.004(-0.014,0.023)$ & 0.632 & - & - \\
\hline \multirow{2}{*}{$\begin{array}{l}\text { College or equivalent } \\
\text { Master's Diploma or } \\
\text { above }\end{array}$} & $0.004(-0.007,0.015)$ & 0.470 & - & - & $0.013(-0.003,0.028)$ & 0.108 & - & - \\
\hline & $0.010(-0.006,0.027)$ & 0.225 & - & - & $0.018(-0.005,0.041)$ & 0.125 & - & - \\
\hline \multicolumn{9}{|l|}{$\begin{array}{l}\text { Annual household } \\
\text { income (RMB 10.000) }\end{array}$} \\
\hline $\begin{array}{c}\text { income }(\text { RIVB } 10,000) \\
<5\end{array}$ & Reference & - & Reference & - & Reference & Reference & - & - \\
\hline 5 to $<10$ & $0.017(0.002,0.031)$ & 0.026 & $0.008(0.000,0.016)$ & 0.042 & $0.019(-0.001,0.039)$ & 0.068 & - & - \\
\hline 10 to $<15$ & $0.009(-0.005,0.024)$ & 0.209 & $-(0.0010)$ & - & $0.011(-0.009,0.032)$ & 0.275 & - & - \\
\hline \multirow{2}{*}{\multicolumn{9}{|c|}{ Healthcare occupation }} \\
\hline & & & & & & & & \\
\hline Yes & Reference & - & - & - & Reference & - & - & - \\
\hline No & $-0.013(-0.028,0.001)$ & 0.070 & - & - & $-0.012(-0.032,0.009)$ & 0.263 & - & - \\
\hline
\end{tabular}

* The $p$ value was adjusted using the false discovery rate method. 


\section{COVID-19 and Influenza Vaccination Willingness among Parents}

Overall, 59.3\% of parents expressed willingness to obtain the COVID-19 vaccination for their child(ren) (Figure S3). The most frequent reason (80.50\%) for willing to be vaccinated was "protecting the people around", while the most frequent reason $(84.80 \%)$ for unwillingness to be vaccinated was "concern about side effects" (Figures S4 and S5). For influenza vaccination, $52.4 \%$ of the parents expressed willingness for their child to be vaccinated. Of the 3009 participants, 1109 (68.8\%) were willing to take both vaccines, and $714(51.1 \%)$ were not willing to take both vaccines (Table S2).

In the multivariate analysis (Table 4), COVID-19 vaccine willingness was associated with educational level. Parents with a college education or below were more likely to accept COVID-19 vaccines than parents with master's diploma or above. Influenza vaccine willingness was associated with the child's age and annual household income. Compared with parents with an annual household income of $\geq \mathrm{RMB} 150,000$, parents with annual household incomes $<$ RMB 150,000 were less likely to accept the influenza vaccine.

Table 4. Univariate and multivariate factors of parental COVID-19 and influenza vaccination acceptance, OR (95\% CI) *.

\begin{tabular}{|c|c|c|c|c|}
\hline \multirow{2}{*}{ Variables } & \multicolumn{2}{|c|}{ COVID-19 Vaccination } & \multicolumn{2}{|c|}{ Influenza Vaccination } \\
\hline & Univariate & Multivariate & Univariate & Multivariate \\
\hline \multicolumn{5}{|l|}{ Children } \\
\hline \multicolumn{5}{|l|}{ Age group } \\
\hline$<1$ & $1.177(0.926,1.497)$ & - & $0.465(0.367,0.590)$ & $0.121(0.374,0.602)$ \\
\hline $1-<2$ & $1.033(0.782,1.364)$ & - & $0.544(0.414,0.714)$ & $0.140(0.422,0.731)$ \\
\hline $2-<3$ & $0.998(0.734,1.357)$ & - & $0.412(0.305,0.557)$ & $0.154(0.310,0.568)$ \\
\hline $3-<4$ & $1.005(0.734,1.376)$ & - & $1.255(0.912,1.727)$ & $0.164(0.909,1.726)$ \\
\hline $4-<5$ & $1.062(0.780,1.448)$ & - & $0.939(0.691,1.276)$ & $0.157(0.678,1.255)$ \\
\hline $5-<6$ & $0.879(0.587,1.317)$ & - & $1.429(0.940,2.172)$ & $0.215(0.891,2.067)$ \\
\hline$\geq 6$ & Reference & & Reference & Reference \\
\hline \multicolumn{5}{|l|}{ Gender } \\
\hline Male & $0.992(0.857,1.147)$ & - & $0.874(0.758,1.009)$ & - \\
\hline Female & Reference & - & Reference & - \\
\hline \multicolumn{5}{|l|}{ Firstborn } \\
\hline No & $0.988(0.847,1.152)$ & - & $0.873(0.751,1.015)$ & - \\
\hline Yes & Reference & - & Reference & - \\
\hline \multicolumn{5}{|l|}{ Parents } \\
\hline \multicolumn{5}{|l|}{ Relationship with child } \\
\hline Mother & $1.024(0.866,1.210)$ & - & $1.262(1.070,1.487)$ & - \\
\hline Father & Reference & - & Reference & - \\
\hline \multicolumn{5}{|l|}{ Age group } \\
\hline$<26$ & $0.997(0.608,1.635)$ & - & $0.370(0.224,0.611)$ & - \\
\hline $26-<31$ & $1.045(0.672,1.624)$ & - & $0.543(0.347,0.849)$ & - \\
\hline $31-<36$ & $0.904(0.583,1.403)$ & - & $0.713(0.456,1.114)$ & - \\
\hline $36-<41$ & $0.753(0.473,1.199)$ & - & $0.886(0.551,1.424)$ & - \\
\hline$\geq 41$ & Reference & - & Reference & - \\
\hline \multicolumn{5}{|l|}{ Educational level } \\
\hline Junior high school or below & $1.563(1.112,2.197)$ & $1.563(1.112,2.197)$ & $0.586(0.416,0.824)$ & - \\
\hline High school graduate or equivalent & $2.139(1.556,2.939)$ & $2.139(1.556,2.939)$ & $0.732(0.534,1.003)$ & - \\
\hline College or equivalent & $1.477(1.116,1.955)$ & $1.477(1.116,1.955)$ & $0.909(0.685,1.206)$ & - \\
\hline Master's Diploma or above & Reference & Reference & Reference & - \\
\hline \multicolumn{5}{|l|}{$\begin{array}{l}\text { Annual household income (RMB } \\
\qquad 10,000)\end{array}$} \\
\hline$<5$ & $1.044(0.777,1.403)$ & - & $0.619(0.462,0.831)$ & $0.153(0.504,0.919)$ \\
\hline $5-<10$ & $1.346(1.124,1.612)$ & - & $0.662(0.554,0.790)$ & $0.093(0.602,0.867)$ \\
\hline $10-<15$ & $1.212(1.007,1.459)$ & - & $0.688(0.573,0.827)$ & $0.096(0.607,0.884)$ \\
\hline$\geq 15$ & Reference & - & Reference & Reference \\
\hline \multicolumn{5}{|l|}{ Healthcare occupation } \\
\hline No & $0.927(0.684,1.257)$ & - & $1.111(0.826,1.495)$ & - \\
\hline Yes & Reference & - & Reference & - \\
\hline
\end{tabular}

* Yes vs. not sure and no. 


\section{The Relationship between Vaccine Hesitancy and Vaccination Willingness}

The correlation between category A VHS scores and category B VHS scores COVID-19 was significant $(r=0.518, p=0.000)$. There was no significant correlation between category A VHS scores and parental willingness to obtain the COVID-19 $(r=-0.007, p=0.689)$ and influenza $(r=-0.001, p=0.947)$ vaccines (Table S3) for their child(ren). Meanwhile, the category B VHS scores were associated with parental willingness to receive the COVID-19 $(r=0.074, p=0.000)$ and influenza $(r=0.157, p=0.000)$ vaccine (Table S3).

\section{Vaccine Hesitancy and Willingness among Healthcare Workers}

Among HCWs, category A VHS scores were significantly higher than category B VHS scores (43.48 \pm 4.34 vs. $42.65 \pm 3.89, p=0.000)$. HCWs showed more agreement on item L1-L4, and L6-L8, compared with parents (Figure 2 and Figure S6). In total, 51.2\% of the HCWs wanted to be vaccinated against COVID-19 (Figure S7). The most frequent reason $(86.36 \%)$ for willing to be vaccinated was "protecting the people around", while the most frequent reason $(80.95 \%)$ for unwillingness to be vaccinated was "concern about side effects" (Figures S8 and S9).

The category A VHS scores and COVID-19 vaccination willingness among parents were not significantly correlated with those among HCWs. In contrast, there was a significant positive correlation between parents and HCWs for category B VHS scores (Figure 3).
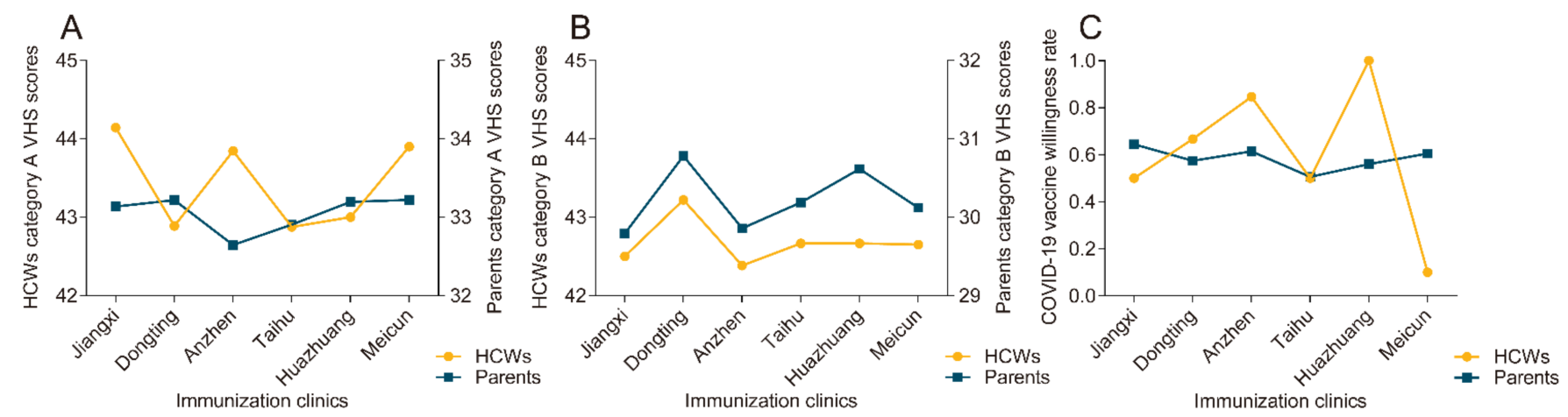

Figure 3. Relationship of vaccine hesitancy and willingness between parents and healthcare workers by immunization clinics. (A) Category A vaccine hesitancy between parents and healthcare workers by immunization clinics, $r=0.143$, $p=0.787$; (B): different category A vaccine hesitancy between parents and healthcare workers by immunization clinics, $r=0.928, p=0.008$; (C): COVID-19 vaccine willingness between parents and healthcare workers by immunization clinics, $r=-0.174, p=0.742$. HCWS $=$ healthcare workers.

\section{Discussion}

This study found that parents were far more hesitant about category B vaccines than category A vaccines in China. The parents showed more confidence toward category A vaccines, as evidenced by the positive responses to items L1-L4 and L6-L8 in the VHS $[27,28]$. More than $50 \%$ of parents expressed willingness for the COVID-19 and influenza vaccinations for their child(ren); more than $50 \%$ of HCWs expressed willingness for the COVID-19 vaccination. There was a significant positive correlation between parents and HCWs for category B VHS scores.

A previous study showed that the implementation of mandatory infant vaccinations is positively associated with the proportion of mothers in favor of vaccinations [33]. In China, parents are more confident in category A vaccines because of their trust in governmentmandated vaccines [13]. In this study, more than $20 \%$ of the parents agreed that their "child/children does or do not need category B vaccines for diseases that are not common anymore". Meanwhile, more than $20 \%$ of the parents also showed hesitancy about this item. Optional vaccines might make parents consider that a category B vaccine is unnecessary. Future vaccine communication programs need to focus on improving the parents' 
confidence in category B vaccines. More qualitative studies should be carried out to explore parents' attitudes toward category B vaccines.

Our study demonstrated that mothers were more hesitant about routine childhood vaccinations than fathers, consistent with previous studies [26,34]. A previous study suggested that men engage in riskier behaviors than do women [14]. A systematic review showed that women were less likely to be vaccinated during the 2009 global influenza pandemic [35]. Moreover, parents of first-born children were more hesitant about category A vaccines, consistent with previous studies $[34,36]$. For a firstborn child's parents, less experience with childhood vaccination might contribute to more vaccine hesitancy [37]. More education for first-time parents, especially mothers, should be implemented to address parental hesitancy on routine vaccinations.

Approximately $40 \%$ of the parents were unwilling to vaccinate their children for COVID-19. Our results were lower than the data reported in the global survey (65\%) [13]. The frequent reason for being unwilling to be vaccinated was "concern about side effects". Our study showed that educational level was an effective predictor associated with COVID19 vaccine willingness, whereas annual household income was an effective predictor associated with influenza vaccine willingness.

Government and health authorities should build a transparent, robust, and reasonable immunization process for COVID-19 vaccines with context-tailored vaccine communication that addresses public concerns. Behavioral-change theories (e.g., the health-belief model and social marketing [38,39]), which have been effectively adapted to improve individual medical use, should be used in developing strategies to improve the acceptance and uptake of COVID-19 vaccinations. Effective communication for COVID-19 vaccines should target those with graduate degrees.

The stratified analyses demonstrated that compared with parents of children aged under 3 years, the parents of children over 3 years were more willing to have their child vaccinated for influenza. However, the average annual incidence of influenza-associated death is the highest among children aged 6-23 months, excluding children aged $<6$ months who cannot receive the influenza vaccine [40]. These findings underline that the uptake of influenza vaccines for children aged $<3$ years in China needs more attention.

Consistent with a previous study, HCWs' hesitancy toward vaccines was concerning [41,42]. HCWs showed a lack of key vaccine knowledge and less confidence in vaccines [42-44]. Approximately 50\% of HCWs showed hesitancy toward COVID-19 vaccination, which remained a concern. The willingness data in our study was lower than $57.5 \%$ in the USA [45]; 71.6\% in France, Belgium and Canada [46]; and 63\% in Hong Kong [47]. HCWs' hesitancy mainly originated from concerns regarding the safety of the COVID19 vaccines. A few combined interventions, including education and training sessions, easy vaccine accessibility, and rewards after vaccination, etc., might increase vaccination uptake [48]. Our study suggests that parental hesitancy toward category B vaccines might be associated with the HCWs' hesitancy toward category B vaccines. Because category $B$ vaccines are optional and billed, recommendations by HCWs have an important role in parents' decisions, especially for first-time parents. Effective interventions need to be implemented to reduce HCWs' hesitancy toward vaccines, as they may also indirectly affect the vaccine hesitancy of parents. Further evidence of the association between parental vaccine hesitancy and HCW vaccine hesitancy is needed.

This study had some limitations that need to be considered when interpreting the findings. First, the study population involved mainly young parents, with $83.1 \%$ aged $<36$ years. The participants were only recruited from vaccination clinics in Wuxi, and 60\% of the children were aged $<3$ years. Selection bias may have limited the representativeness of the sample. Second, vaccine hesitancy and vaccine willingness are influenced by many complex factors, which might vary across different times, policies, and health systems. The willingness to obtain COVID-19 vaccination might vary. Third, in the actual survey, parents filled out the questionnaire while taking care of their children. If the child was crying, it may have affected the parents' attention to the survey. Fourth, more influencing factors 
associated with vaccine hesitancy and vaccine willingness should be identified. Fifth, COVID-19 vaccinations for children are not yet approved. However, obtaining data on Chinese parents' intentions toward COVID-19 vaccines could help inform the development of child-immunization policies in the future. Finally, the association between parental vaccine hesitancy and HCW vaccine hesitancy was assessed only in a small sample size. More efforts are needed in sampling-size selection and survey methods.

\section{Conclusions}

In China, parents are more hesitant about category $B$ vaccines than category A vaccines. More than $40 \%$ of parents surveyed expressed hesitancy or refusal of the COVID-19 and influenza vaccinations. Parental hesitancy about category B vaccines was associated with parental willingness to receive a COVID-19 vaccine. Further, parental hesitancy toward category $\mathrm{B}$ vaccines was associated with $\mathrm{HCW}$ hesitancy toward category $\mathrm{B}$ vaccines. Effective interventions need to be implemented to address parental vaccine hesitancy and improve vaccine uptake.

Supplementary Materials: The following are available online at https:/ /www.mdpi.com/article/10 .3390 /vaccines9040342/s1, Figure S1: Wuxi city in China, Figure S2: Areas and Counties in Wuxi city, Figure S3: Parental acceptance of vaccination against COVID-19 and influenza for child, Figure S4: Reasons being willing to accept vaccine against COVID-19, Figure S5: Reasons being not willing to accept vaccine against COVID-19, Figure S6: Distribution of responses to 10-item of the vaccine hesitancy scale for healthcare workers, Figure S7: Healthcare workers' acceptance of vaccination against COVID-19, Figure S8: Reasons being willing to accept vaccine against COVID-19 for healthcare workers, Figure S9: Reasons being not willing to accept vaccine against COVID-19 for healthcare workers, Table S1: Vaccine hesitancy scale scores by participant's socio-demographics $(n=3009)$, Table S2: Comparisons to COVID-19 and influenza vaccine acceptance by sociodemographics $(n=3009)$, Table S3: Relationship between vaccine hesitancy with COVID-19 and influenza vaccination acceptance: Supplementary 2: Method.

Author Contributions: Conceptualization, Q.W., H.J., and L.L.; methodology, H.J.; software, H.J.; validation, H.J., B.L., and L.L.; formal analysis, Q.W., S.X., L.L., and H.J.; investigation, Q.W., S.Z., J.W., Y.H. (Ying Han), S.D., J.H., T.C., L.Y., N.S., M.L., Y.H. (Yue Han), Y.S. and E.C.; resources, B.L.; data curation, Q.W., S.X., S.Z., X.W. and L.L.; writing—original draft preparation, Q.W., H.J., and L.L.; writing-review and editing, Q.W., H.J., and L.L.; visualization, Q.W., H.J., and L.L.; supervision, H.J., and L.L.; project administration, Q.W., H.J., and B.L.; funding acquisition, Q.W., H.J., S.X., B.L., and L.L. All authors have read and agreed to the published version of the manuscript.

Funding: This work was supported by Wuxi City Technology Development Fund (N20191007); Postgraduate Research and Practice Innovation Program of Jiangsu Province (KYCX20_0153); Jiangsu Provincial Six Talent Peak (grant number: WSN-002); Public Health Research Center of Jiangnan University (No. JUPH201845); the UK Foreign, Commonwealth and Development Office; and Wellcome [215373/A/19/Z].

Institutional Review Board Statement: All subjects gave their informed consent for inclusion before they participated in the study. The study was conducted in accordance with the Declaration of Helsinki, and the protocol was approved by the Ethics Committee of Wuxi Center for Disease Control and Prevention (2020No10).

Informed Consent Statement: Informed consent was obtained from all participants.

Conflicts of Interest: The authors declare no conflict of interest.

\section{References}

1. World Health Organization. Ten Threats to Global Health in 2019. Available online: https://www.who.int/newsroom/featurestories/ten-threats-toglobal-health-in-2019 (accessed on 18 June 2020).

2. MacDonald, N.E.; SAGE Working Group on Vaccine Hesitancy. Vaccine hesitancy: Definition, scope and determinants. Vaccine 2015, 33, 4161-4164. [CrossRef] [PubMed]

3. Phadke, V.K.; Bednarczyk, R.A.; Salmon, D.A.; Omer, S.B. Association Between Vaccine Refusal and Vaccine-Preventable Diseases in the United States: A Review of Measles and Pertussis. JAMA 2016, 315, 1149-1158. [CrossRef] [PubMed] 
4. Yang, W. Transmission dynamics of and insights from the 2018-2019 measles outbreak in New York City: A modeling study. Sci. Adv. 2020, 6, eaaz4037. [CrossRef] [PubMed]

5. Nicolay, N.; Mirinaviciute, G.; Mollet, T.; Celentano, L.P.; Bacci, S. Epidemiology of measles during the COVID-19 pandemic, a description of the surveillance data, 29 EU/EEA countries and the United Kingdom, January to May 2020. Euro. Surveill. 2020, 25, 2001390. [CrossRef] [PubMed]

6. Kempe, A.; Saville, A.W.; Albertin, C.; Zimet, G.; Breck, A.; Helmkamp, L.; Vangala, S.; Dickinson, L.M.; Rand, C.; Humiston, S.; et al. Parental Hesitancy About Routine Childhood and Influenza Vaccinations: A National Survey. Pediatrics 2020, 146, e20193852. [CrossRef] [PubMed]

7. Paterson, P.; Chantler, T.; Larson, H.J. Reasons for non-vaccination: Parental vaccine hesitancy and the childhood influenza vaccination school pilot programme in England. Vaccine 2018, 36, 5397-5401. [CrossRef] [PubMed]

8. Tuckerman, J.; Crawford, N.W.; Marshall, H.S. Disparities in parental awareness of children's seasonal influenza vaccination recommendations and influencers of vaccination. PLoS ONE 2020, 15, e0230425. [CrossRef] [PubMed]

9. Fogel, B.N.; Hicks, S.D. “Flu-Floppers": Factors Influencing Families' Fickle Flu Vaccination Patterns. Clin. Pediatr. 2020, 59, 352-359. [CrossRef] [PubMed]

10. AlHajri, B.; Alenezi, D.; Alfouzan, H.; Altamimi, S.; Alzalzalah, S.; Almansouri, W.; Ziyab, A.H. Willingness of parents to vaccinate their children against influenza and COVID-19. J. Pediatr. 2020. [CrossRef]

11. Goldman, R.D.; McGregor, S.; Marneni, S.R.; Katsuta, T.; Griffiths, M.A.; Hall, J.E.; Seiler, M.; Klein, E.J.; Cotanda, C.P.; Gelernter, R.; et al. Willingness to Vaccinate Children against Influenza after the Coronavirus Disease 2019 Pandemic. J. Pediatr. 2021, 228, 87-93.e2. [CrossRef]

12. World Health Organization. Coronavirus Disease 2019 (COVID-19) Situation Report [Internet]. Available online: https:/ /www. who.int/ (accessed on 29 January 2021).

13. Lazarus, J.V.; Ratzan, S.C.; Palayew, A.; Gostin, L.O.; Larson, H.J.; Rabin, K.; El-Mohandes, A. A global survey of potential acceptance of a COVID-19 vaccine. Nat. Med. 2021, 27, 225-228. [CrossRef]

14. Goldman, R.D.; Yan, T.D.; Seiler, M.; Cotanda, C.P.; Brown, J.C.; Klein, E.J.; Hoeffe, J.; Gelernter, R.; Hall, J.E.; Davis, A.L.; et al. Caregiver willingness to vaccinate their children against COVID-19: Cross sectional survey. Vaccine 2020, 38, 7668-7673. [CrossRef]

15. Anderson, R.M.; Vegvari, C.; Truscott, J.; Collyer, B.S. Challenges in creating herd immunity to SARS-CoV-2 infection by mass vaccination. Lancet 2020, 396, 1614-1616. [CrossRef]

16. Hu, Y.; Chen, Y.; Liang, H.; Wang, Y. Reliability and validity of a survey to identify vaccine hesitancy among parents in Changxing county, Zhejiang province. Hum. Vaccin Immunother. 2019, 15, 1092-1099. [CrossRef]

17. Wang, Q.; Yue, N.; Zheng, M.Y.; Wang, D.; Duan, C.; Yu, X.; Zhang, X.; Bao, C.; Jin, H. Influenza vaccination coverage of population and the factors influencing influenza vaccination in mainland China: A meta-analysis. Vaccine 2018, 36, 7262-7269. [CrossRef]

18. Lin, Y.; Hu, Z.; Zhao, Q.; Alias, H.; Danaee, M.; Wong, L.P. Understanding COVID-19 vaccine demand and hesitancy: A nationwide online survey in China. PLoS Negl. Trop Dis. 2020, 14, e0008961. [CrossRef]

19. Yang, R.; Penders, B.; Horstman, K. Vaccine Hesitancy in China: A Qualitative Study of Stakeholders' Perspectives. Vaccines 2020, 8, 650. [CrossRef]

20. Rong, H.; Lai, X.; Ma, X.; Hou, Z.; Li, S.; Jing, R.; Zhang, H.; Peng, Z.; Feng, L.; Fang, H. Seasonal Influenza Vaccination and Recommendation: The Difference between General Practitioners and Public Health Workers in China. Vaccines 2020, 8, 265. [CrossRef]

21. Lama, Y.; Hancock, G.R.; Freimuth, V.S.; Jamison, A.M.; Quinn, S.C. Using classification and regression tree analysis to explore parental influenza vaccine decisions. Vaccine 2020, 38, 1032-1039. [CrossRef]

22. Wuxi Municipal Bureau of Statistics. Wuxi Data [Internet]. Available online: http://yw.tj.wuxi.gov.cn:8081/pc/ (accessed on 18 December 2020).

23. Tang, X.; Geater, A.; McNeil, E.; Zhou, H.; Deng, Q.; Dong, A. Timeliness and completeness of measles vaccination among children in rural areas of Guangxi, China: A stratified three-stage cluster survey. J. Epidemiol 2017, 27, 317-324. [CrossRef]

24. Jiangsu Province Bureau of Statistics. 2020 Jiangsu Statistical Yearbook [Internet]. Available online: http://tj.jiangsu.gov.cn/2020 /nj20.htm (accessed on 18 December 2020).

25. Larson, H.J.; Jarrett, C.; Schulz, W.S.; Chaudhuri, M.; Zhou, Y.; Dube, E.; Schuster, M.; MacDonald, N.E.; Wilson, R. Measuring vaccine hesitancy: The development of a survey tool. Vaccine 2015, 33, 4165-4175. [CrossRef] [PubMed]

26. Ren, J.; Wagner, A.L.; Zheng, A.; Sun, X.; Boulton, M.L.; Huang, Z.; Zikmund-Fisher, B.J. The demographics of vaccine hesitancy in Shanghai, China. PLoS ONE 2018, 13, e0209117. [CrossRef] [PubMed]

27. Domek, G.J.; O’Leary, S.T.; Bull, S.; Bronsert, M.; Contreras-Roldan, I.L.; Ventura, G.A.B.; Kempe, A.; Asturias, E.J. Measuring vaccine hesitancy: Field testing the WHO SAGE Working Group on Vaccine Hesitancy survey tool in Guatemala. Vaccine 2018, 36, 5273-5281. [CrossRef] [PubMed]

28. Shapiro, G.K.; Tatar, O.; Dube, E.; Amsel, R.; Knauper, B.; Naz, A.; Perez, S.; Rosberger, Z. The vaccine hesitancy scale: Psychometric properties and validation. Vaccine 2018, 36, 660-667. [CrossRef] [PubMed]

29. van Buuren, S.; Groothuis-Oudshoorn, K. mice: Multivariate Imputation by Chained Equations in, R.J. Stat. Softw 2011, 45, 1-67. 
30. Wagner, A.L.; Masters, N.B.; Domek, G.J.; Mathew, J.L.; Sun, X.; Asturias, E.J.; Ren, J.; Huang, Z.; Contreras-Roldan, I.L.; Gebremeskel, B.; et al. Comparisons of Vaccine Hesitancy across Five Low- and Middle-Income Countries. Vaccines $2019,7,155$. [CrossRef] [PubMed]

31. Bolker, B.M.; Brooks, M.E.; Clark, C.J.; Geange, S.W.; Poulsen, J.R.; Stevens, M.H.H.; White, J.-S.S. Generalized linear mixed models: A practical guide for ecology and evolution. Trends Ecol. Evol. 2009, 24, 127-135. [CrossRef] [PubMed]

32. Glickman, M.E.; Rao, S.R.; Schultz, M.R. False discovery rate control is a recommended alternative to Bonferroni-type adjustments in health studies. J. Clin. Epidemiol. 2014, 67, 850-857. [CrossRef]

33. Martinot, A.; Leboucher, B.; Cohen, R.; Stahl, J.P.; Subtil, D.; Pujol, P.; Lepetit, H.; Longfier, L.; Gaudelus, J. Evolution between 2008 and 2018 of mothers' perception regarding vaccination and infant vaccine coverage in France. Infect. Dis. Now 2021, 51, 153-158. [CrossRef]

34. Yufika, A.; Wagner, A.L.; Nawawi, Y.; Wahyuniati, N.; Anwar, S.; Yusri, F.; Haryanti, N.; Wijayanti, N.P.; Rizal, R.; Fitriani, D.; et al. Parents' hesitancy towards vaccination in Indonesia: A cross-sectional study in Indonesia. Vaccine 2020, 38, 2592-2599. [CrossRef]

35. Bish, A.; Yardley, L.; Nicoll, A.; Michie, S. Factors associated with uptake of vaccination against pandemic influenza: A systematic review. Vaccine 2011, 29, 6472-6484. [CrossRef]

36. Corben, P.; Leask, J. Vaccination hesitancy in the antenatal period: A cross-sectional survey. BMC Public Health 2018, 18, 566. [CrossRef]

37. Mohd Azizi, F.S.; Kew, Y.; Moy, F.M. Vaccine hesitancy among parents in a multi-ethnic country, Malaysia. Vaccine 2017, 35, 2955-2961. [CrossRef]

38. Opel, D.J.; Diekema, D.S.; Lee, N.R.; Marcuse, E.K. Social Marketing as a Strategy to Increase Immunization Rates. Arch. Pediatr Adolesc Med. 2009, 163, 432-437. [CrossRef]

39. Lin, L.; Sun, R.; Yao, T.; Zhou, X.; Harbarth, S. Factors influencing inappropriate use of antibiotics in outpatient and community settings in China: A mixed-methods systematic review. BMJ Glob. Health 2020, 5, e003599. [CrossRef]

40. Shang, M.; Blanton, L.; Brammer, L.; Olsen, S.J.; Fry, A.M. Influenza-Associated Pediatric Deaths in the United States, $2010-2016$. Pediatrics 2018, 141, e20172918. [CrossRef]

41. Wilson, R.; Zaytseva, A.; Bocquier, A.; Nokri, A.; Fressard, L.; Chamboredon, P.; Carbonaro, C.; Bernardi, S.; Dubé, E.; Verger, P.; et al. Vaccine hesitancy and self-vaccination behaviors among nurses in southeastern France. Vaccine 2020, 38, 1144-1151. [CrossRef]

42. Di Martino, G.; Di Giovanni, P.; Di Girolamo, A.; Scampoli, P.; Cedrone, F.; D’Addezio, M.; Staniscia, T. Knowledge and Attitude towards Vaccination among Healthcare Workers: A Multicenter Cross-Sectional Study in a Southern Italian Region. Vaccines 2020, 8, 248. [CrossRef]

43. Picchio, C.A.; Carrasco, M.G.; Sagué-Vilavella, M.; Rius, C. Knowledge, attitudes and beliefs about vaccination in primary healthcare workers involved in the administration of systematic childhood vaccines, Barcelona, 2016/17. Euro. Surveill 2019, 24, 1800117. [CrossRef]

44. Karafillakis, E.; Dinca, I.; Apfel, F.; Cecconi, S.; Wűrz, A.; Takacs, J.; Suk, J.; Celentano, L.P.; Kramarz, P.; Larson, H.J. Vaccine hesitancy among healthcare workers in Europe: A qualitative study. Vaccine 2016, 34, 5013-5020. [CrossRef]

45. Shaw, J.; Stewart, T.; Anderson, K.B.; Hanley, S.; Thomas, S.J.; Salmon, D.A.; Morley, C. Assessment of US health care personnel (HCP) attitudes towards COVID-19 vaccination in a large university health care system. Clin. Infect. Dis 2021, ciab054. [CrossRef]

46. Verger, P.; Scronias, D.; Dauby, N.; Adedzi, K.A.; Gobert, C.; Bergeat, M.; Gagneur, A.; Dubé, E. Attitudes of healthcare workers towards COVID-19 vaccination: a survey in France and French-speaking parts of Belgium and Canada, 2020. Eurosurveillance 2021, 26, 2002047. [CrossRef]

47. Kwok, K.O.; Li, K.K.; Wei, W.I.; Tang, A.; Wong, S.Y.S.; Lee, S.S. Editor's Choice: Influenza vaccine uptake, COVID-19 vaccination intention and vaccine hesitancy among nurses: A survey. Int. J. Nurs Stud. 2021, 114, 103854. [CrossRef]

48. Rashid, H.; Yin, J.K.; Ward, K.; King, C.; Seale, H.; Booy, R. Assessing Interventions To Improve Influenza Vaccine Uptake Among Health Care Workers. Health Aff. 2016, 35, 284-292. [CrossRef] 